OPEN ACCESS

Edited by:

Olga Matos,

New University of Lisbon, Portugal

Reviewed by:

Anne Totet,

University of Picardie Jules

Verne, France

Francisco Antunes,

Universidade de Lisboa, Portugal

*Correspondence:

Qingyuan Zhan

drzhanqy@163.com

Specialty section:

This article was submitted to Infectious Diseases-Surveillance,

Prevention and Treatment,

a section of the journal

Frontiers in Public Health

Received: 13 March 2021

Accepted: 10 May 2021

Published: 16 June 2021

Citation:

Wang $Y$, Zhou X, Saimi M, Huang $X$, Sun T, Fan G and Zhan Q (2021) Risk

Factors of Mortality From

Pneumocystis Pneumonia in Non-HIV

Patients: A Meta-Analysis.

Front. Public Health 9:680108.

doi: 10.3389/fpubh.2021.680108

\section{Risk Factors of Mortality From Pneumocystis Pneumonia in Non-HIV Patients: A Meta-Analysis}

\author{
Yuqiong Wang ${ }^{1}$, Xiaoyi Zhou ${ }^{1}$, Maidinuer Saimi ${ }^{2}$, Xu Huang ${ }^{3,4}$, Ting Sun ${ }^{2}$, Guohui Fan ${ }^{5,6}$ \\ and Qingyuan Zhan ${ }^{3,4 *}$ \\ ${ }^{1}$ Peking University China-Japan Friendship School of Clinical Medicine, Beijing, China, ${ }^{2}$ Department of Pulmonary and \\ Critical Care Medicine, Center of Respiratory Medicine, China-Japan Friendship Hospital, Capital Medical University, Beijing, \\ China, ${ }^{3}$ Department of Pulmonary and Critical Care Medicine, Center of Respiratory Medicine, China-Japan Friendship \\ Hospital, Beijing, China, ${ }^{4}$ National Center for Respiratory Medicine, Beijing, China, ${ }^{5}$ Institute of Clinical Medical Sciences, \\ China-Japan Friendship Hospital, Beijing, China, ${ }^{6}$ Institute of Respiratory Medicine, Chinese Academy of Medical Sciences, \\ National Clinical Research Center for Respiratory Disease, National Center for Respiratory Disease, Beijing, China
}

Background: We performed a meta-analysis to systematically review the risk factors of mortality from non-HIV-related Pneumocystis pneumonia (PcP) and provide the theoretical basis for managing non-HIV-related PcP.

Methods: PubMed, Embase, Web of Science, the Cochrane Library and CNKI databases were searched. A meta-analysis of the risk factors of mortality from non-HIV-related PCP was conducted.

Results: A total of 19 studies and 1,310 subjects were retrieved and included in the meta-analysis, including 485 and 825 patients in the non-survivor and survivor groups, respectively. In the primary analysis, age, concomitant with other pulmonary diseases at diagnosis of PcP, solid tumors, cytomegalovirus(CMV) co-infection, lactate dehydrogenase $(\mathrm{LDH})$, lymphocyte count, invasive ventilation during hospitalization, and pneumothorax were associated with mortality from non-HIV-related PCP, whereas sex, albumin, PcP prophylaxis, use of corticosteroids after admission, and time from onset of symptoms to treatment were not associated with mortality from non-HIV-related PcP.

Conclusions: The mortality rate of non-HIV-infected patients with PCP was still high. Age, concomitant with other pulmonary diseases at diagnosis of PcP, solid tumors, CMV co-infection, LDH, lymphocyte count, invasive ventilation during hospitalization, and pneumothorax were risk factors of mortality from non-HIV-related PCP. Improved knowledge of prognostic factors is crucial to guide early treatment.

Keywords: Pneumocystis pneumonia, non-HIV, mortality, risk factors, pneumonia

\section{INTRODUCTION}

Pneumocystis pneumonia $(\mathrm{PcP})$ is a potentially life-threatening infection that occurs in immunocompromised patients (1). Recent investigations have reported a decrease in PcP incidence in human immunodeficiency virus (HIV) patients due to the advent of highly active antiretroviral therapy (HAART) and chemoprophylaxis (2). Conversely, the incidence of PcP, which has been increasing in immunocompromised patients without HIV during the last decades, has been 
attributed to the increasing number of patients at risk who are receiving corticosteroids or other immunosuppressive medications for allogeneic bone marrow or organ transplant, malignancies, and autoimmune inflammatory diseases (3). In non-HIV immunocompromised patients with $\mathrm{PcP}$ infection, there is a significant risk of morbidity and mortality, and the prognosis is dismal once mechanical ventilation for respiratory failure is required (4). Several studies have attempted to explore the risk factors influencing the mortality in non-HIV patients with $\mathrm{PcP}$. This meta-analysis was performed to explore the risk factors of mortality from PcP in non-HIV patients.

\section{MATERIALS AND METHODS}

\section{Search Strategy}

A search of PubMed, Embase, Web of Science, the Cochrane Library and CNKI databases were undertaken comprehensively and systematically for case-control and cohort studies published up to July 2020 on risk factors of death in non-HIV patients with $\mathrm{PcP}$. The references were retroactively included to supplement and access relevant literature. The retrieval adopted a method of combining subject words with free words. English search terms included the synonyms of domains (pneumonia, pneumocystis) and (non-HIV), determinant (risk factors), and outcome (death).

\section{Inclusion and Exclusion Criteria}

Studies were included if they fulfilled the following criteria: (1) case-control or cohort studies including non-HIV patients with PcP; (2) studies exploring the risk factors of death in-hospital or within 30 days of $\mathrm{PcP}$ in non-HIV patients (to ensure the consistency of outcome indicators). The exclusion criteria were defined as follows: (1) patients aged $<18$ years; (2) repeated publications; (3) defective or poor quality of study; (4) reviews, case reports, meta-analyses, opinions, and summaries.

\section{Literature Selection and Data Extraction}

Two researchers (YW and XZ) independently conducted literature screening, data extraction, and quality evaluation of the included studies. In the literature screening process, the title and abstract were first read. After excluding the literature that did not meet the inclusion criteria, the full text of the remaining literature was read to determine whether it should be included in the metaanalysis. The authors were contacted by email or telephone to supplement where the data were incomplete.

\section{Study Quality Assessment}

The New castle Ottawa Scale (NOS) (5), which is quite comprehensive and has been partially validated for evaluating the quality of observational studies in meta-analyses. Table $\mathbf{1}$ shows the quality assessment based on the NOS guidelines. High-quality literature was classified as $\geq 6$ points, and most studies were rated as having reasonable to good quality, with a low risk of bias. In some studies, a small number of cases, different definitions of the analyzed risk factors, and dissimilarity of the populations were the main weaknesses. Data extraction and quality assessment were conducted independently by two authors and discussed with a third investigator when there was disagreement. Since this was a review of already published data, written informed consent was waived by the ethics committee.

\section{Statistical Analysis}

RevMan software (version 5.3; Cochrane Collaboration, Oxford, UK) was used for the meta-analysis. For the categorical outcomes, the odds ratio (OR) was calculated as the effect size, and for the continuous outcomes, the mean difference (MD) was used as the effect size. Statistical heterogeneity in publications was determined using the $I^{2}$ statistic. The fixed-effect model was chosen as the main analysis method since heterogeneity was confirmed as not statistically significant. At least five studies reported on the outcome of interest, all of which were two-sided, and the statistical significance was set at the 0.05 level.

\section{RESULTS}

\section{Literature Search}

A total of 404 papers were obtained for the initial screening. Finally, 19 articles, which met the inclusion criteria, were included (6-24). The 19 studies included 1,310 patients (485 and 825 in the non-survivor and survivor groups, respectively). The process of literature screening and selection are presented in Figure 1.

\section{Characteristics of the Articles Included and the Results of the Bias Risk Assessment}

Table 1 details the basic features of the included articles and the results of the bias risk assessment according to the NOS. Of the 19 included studies, 17 used the case-control study design (6-13, 1624) while two used a retrospective cohort design $(14,15)$. Four studies were performed in China $(7,18,22,23)$, four in Korea (10-13), four in Japan $(6,9,19,21)$, one in Taiwan (17), one in Turkey (15), one in Greece (14), one in Israel (8) and three in France $(16,20,24)$. The sample sizes of these studies ranged from 20 to 173 . More male patients were included (mean, 58\%), and the mean age of the population ranged from 39 to 69 years.

Tables 2, 3 summarize the relevant information on the meta-analysis of modifiable and non-modifiable risk factors, respectively.

\section{Meta-Analysis Results Non-modifiable Factors}

Age: fourteen studies (6-10, 12, 13, 16, 17, 20-24) were included, with 391 and 599 patients in the non-survivor and group, respectively. The results showed that age was a risk factor of mortality from $\mathrm{PcP}$ in non-HIV patients (mean difference $=6.61$, 95\% CI 4.48 to $8.74, P<0.00001$; Figure $2 \mathrm{~A}$ ). No significant heterogeneity was found in this analysis $\left(I^{2}=20 \%, P=0.24\right)$.

Sex: thirteen studies $(6-10,12,13,15,16,18,21-23)$ were included, with 364 and 584 patients in the non-survivor and survivor groups, respectively. The results showed that sex was not a risk factor of mortality from $\mathrm{PcP}$ in non-HIV patients (OR 1.02 , 95\% CI 0.77 to $1.35, P=0.90$; Figure $2 B$ ). No significant heterogeneity was found in this analysis $\left(I^{2}=23 \%, P=0.21\right)$.

Concomitant with other pulmonary diseases at diagnosis of PcP: six studies $(6,7,9,10,17,22)$ were included, with 
TABLE 1 | Characteristics and Newcastle-Ottawa scale quality score of included studies.

\begin{tabular}{|c|c|c|c|c|c|c|c|c|}
\hline References & Study type & NOS & Country & Number of patients & Period & Mean age, $y$ & Male, (\%) & Outcome \\
\hline Asai et al. (6) & Case-control study & 8 & Japan & 38 & 2005-2012 & NA & NA & 30-day mortality \\
\hline Chen et al. (7) & Case-control study & 8 & China & 69 & 2004-2013 & 39 & 25 (36.23\%) & In-hospital mortality \\
\hline Hardak et al. (8) & Case-control study & 8 & Israel & 58 & 2005-2010 & 56 & $28(48.3 \%)$ & In-hospital mortality \\
\hline Kageyama et al. (9) & Case-control study & 8 & Japan & 95 & 2000-2015 & 69 & 57 (60\%) & In-hospital mortality \\
\hline Kim et al. (10) & Case-control study & 6 & Korea & 173 & 2004-2011 & 56 & 116(67.05\%) & In-hospital mortality \\
\hline Kim et al. (11) & Cohort study & 7 & Korea & 76 & 2014-2015 & 55 & $53(65 \%)$ & 30-day mortality \\
\hline Ko et al. (12) & Case-control study & 8 & Korea & 51 & 2005-2018 & 52 & 35 (68.6\%) & In-hospital mortality \\
\hline Ko et al. (13) & Case-control study & 7 & Korea & 48 & 2005-2011 & 53 & 33 (69\%) & In-hospital mortality \\
\hline Kofteridis et al. (14) & Cohort study & 8 & Greece & 62 & 2004-2013 & 65 & 43 (69.35\%) & In-hospital mortality \\
\hline Korkmaz et al. (15) & Cohort study & 7 & Turkey & 43 & 2009-2015 & 57 & 30 (69.8\%) & 30-day mortality \\
\hline Lemiale et al. (16) & Case-control study & 7 & France & 139 & 1988-2011 & 48 & 79 (56.8\%) & ICU mortality \\
\hline Li et al. (17) & Case-control study & 8 & Taiwan & 20 & 2008-2011 & 50 & $9(45 \%)$ & In-hospital mortality \\
\hline Liu et al. (18) & Case-control study & 8 & China & 57 & 2013-2018 & 48 & $29(50.8 \%)$ & In-hospital mortality \\
\hline Matsumura et al. (19) & Case-control study & 7 & Japan & 82 & 2005-2010 & 64 & $51(62 \%)$ & 30-day mortality \\
\hline Roblot et al. (20) & Case-control study & 7 & France & 102 & 1995-1999 & 57 & $61(59 \%)$ & 30-day mortality \\
\hline Tamai et al. (21) & Case-control study & 8 & Japan & 29 & 2006-2012 & 59 & 14 (48\%) & In-hospital mortality \\
\hline Weng et al. (22) & Case-control study & 8 & China & 82 & 2012-2015 & 53 & 34 (41.5\%) & In-hospital mortality \\
\hline Ye et al. (23) & Case-control study & 8 & China & 47 & 2003-2012 & 49 & 21 (44.68\%) & 30-day mortality \\
\hline Zahar et al. (24) & Case-control study & 8 & France & 39 & 1989-1999 & 48 & 20 (52.2\%) & 30-day mortality \\
\hline
\end{tabular}

ICU, intensive care unit; NA, not available; NOS, Newcastle-Ottawa Scale.

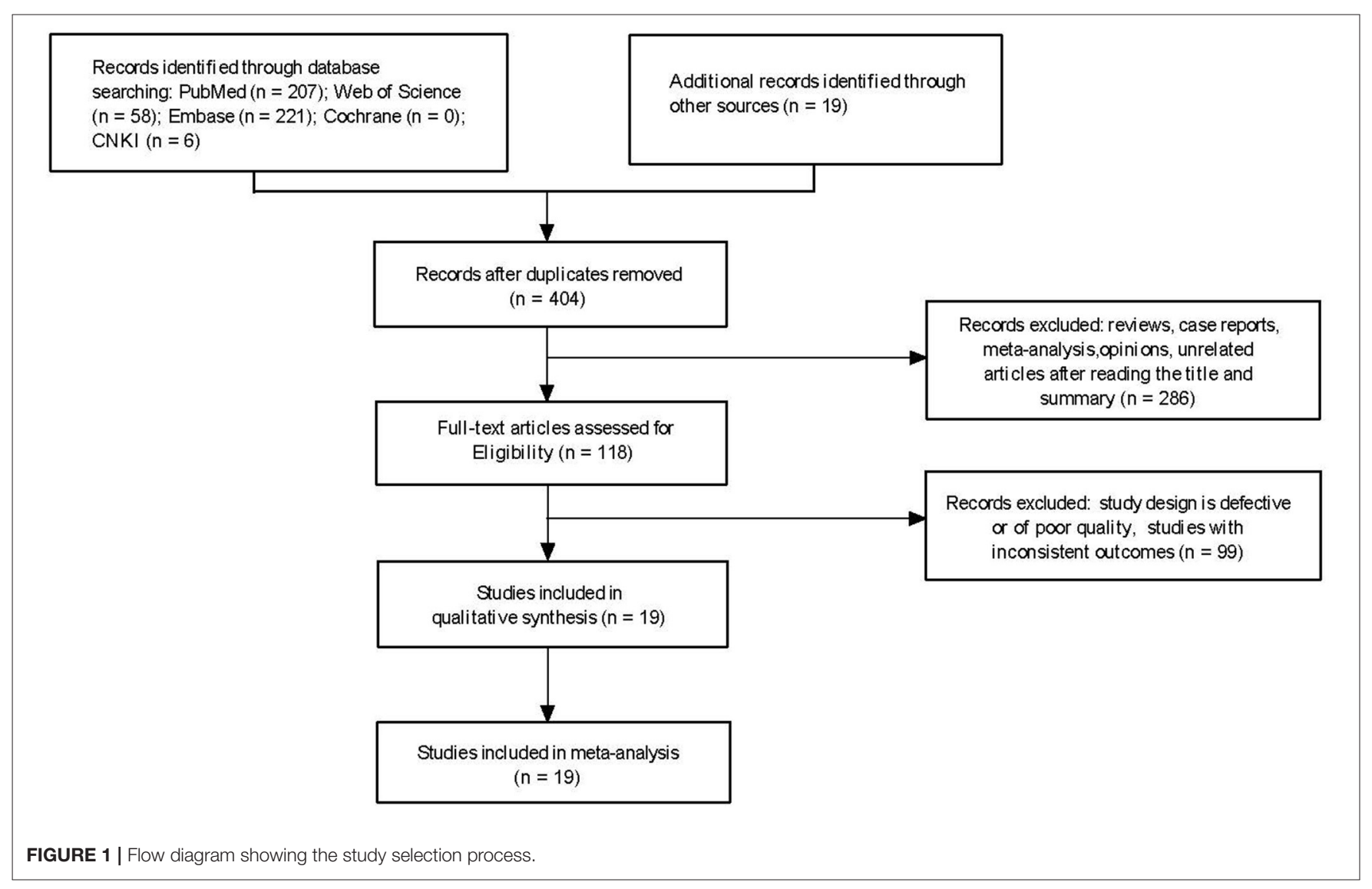


TABLE 2 | Summary of meta-analysis results of non-modifiable factors for mortality in non-HIV-related Pneumocystis pneumonia.

\begin{tabular}{|c|c|c|c|c|c|c|c|}
\hline Factors & No. study & Sample (n) & $\begin{array}{c}\text { Heterogeneity test } \\
\qquad \boldsymbol{P} \text {-value }\end{array}$ & $\begin{array}{l}\text { Effects model } \\
\qquad I^{2}(\%)\end{array}$ & OR/MD (95\% Cl) & $P$-value & \\
\hline Age & 14 & 990 & 0.24 & 20 & Fixed effects model & $6.61(4.48-8.74)$ & $<0.00001$ \\
\hline Sex & 13 & 948 & 0.21 & 23 & Fixed effects model & $1.02(0.77-1.35)$ & 0.9 \\
\hline $\begin{array}{l}\text { Concomitant with other } \\
\text { pulmonary diseases at } \\
\text { diagnosis of PCP }\end{array}$ & 6 & 477 & 0.52 & 0 & Fixed effects model & $3.42(1.96-5.96)$ & $<0.0001$ \\
\hline
\end{tabular}

$\mathrm{Cl}$, confidence interval; $\mathrm{MD}$, mean difference; OR, odds ratio.

TABLE 3 | Summary of meta-analysis results of modifiable factors for mortality in non-HIV-related Pneumocystis pneumonia.

\begin{tabular}{|c|c|c|c|c|c|c|c|}
\hline Factors & No. study & Sample $(n)$ & $\begin{array}{l}\text { Heterogeneity test } \\
\qquad \boldsymbol{P} \text {-value }\end{array}$ & $\begin{array}{l}\text { Effects model } \\
\qquad\left.\right|^{2}(\%)\end{array}$ & OR/MD (95\% Cl) & $P$-value & \\
\hline Cytomegalovirus & 5 & 287 & 0.21 & 32 & Fixed effects model & $3.59(1.91-6.75)$ & $<0.0001$ \\
\hline Pneumothorax & 6 & 340 & 0.45 & 0 & Fixed effects model & $2.55(1.13-5.77)$ & 0.02 \\
\hline PCP prophylaxis & 7 & 640 & 0.67 & 0 & Fixed effects model & $1.43(0.75-2.71)$ & 0.28 \\
\hline $\begin{array}{l}\text { Corticosteroid after } \\
\text { admission }\end{array}$ & 8 & 675 & 0.36 & 8 & Fixed effects model & $1.44(0.94-2.22)$ & 0.1 \\
\hline Invasive ventilation & 12 & 849 & 0.01 & 54 & Random effects model & 29.24 (13.09-65.33) & $<0.00001$ \\
\hline Lactate dehydrogenase & 9 & 538 & 0.002 & 67 & Random effects model & $91.12(1.16-181.09)$ & 0.05 \\
\hline Albumin & 9 & 618 & $<0.00001$ & 88 & Random effects model & $-0.18(-0.46-0.10)$ & 0.22 \\
\hline Lymphocyte count & 10 & 711 & 0.03 & 51 & Random effects model & $-0.25(-0.39-0.10)$ & 0.0008 \\
\hline $\begin{array}{l}\text { Time from onset of } \\
\text { symptoms to treatment }\end{array}$ & 6 & 499 & 0.007 & 69 & Random effects model & $1.9(-1.18-4.99)$ & 0.23 \\
\hline
\end{tabular}

$\mathrm{Cl}$, confidence interval; $\mathrm{MD}$, mean difference; OR, odds ratio; PCP, Pneumocystis pneumonia.

213 and 264 patients in the non-survivor and survivor groups, respectively. The Results showed that concomitant with other pulmonary diseases at diagnosis of $\mathrm{PcP}$ was a risk factor of mortality from PcP in non-HIV patients (OR 3.42, 95\% CI, 1.96 to 5.96; $P<0.0001$; Figure 2C). No significant heterogeneity was found in this analysis $\left(I^{2}=0 \%, P=0.52\right)$.

Solid tumors:six studies $(8,10,14,16,17,22)$ were included, with 200 and 334 patients in the non-survivor and survivor groups, respectively. The results showed that solid tumors were a risk factor of mortality from $\mathrm{PcP}$ in non-HIV patients (OR 2.06, 95\% CI, 1.32 to $3.21 ; P=0.002$; Figure 2D). No significant heterogeneity was found in this analysis $\left(I^{2}=0 \%, P=0.46\right)$.

\section{Modifiable Risk Factors}

Cytomegalovirus (CMV) co-infection: five studies $(7,11-13,15)$ were included, with 113 and 174 patients in the non-survivor and survivor groups, respectively. The results showed that lung disease was a risk factor of mortality from $\mathrm{PcP}$ in non-HIV patients (OR 3.59, 95\% CI 1.91 to 6.75, $P<0.0001$; Figure 3A). No significant heterogeneity was found in this analysis $\left(I^{2}=32 \%, P=0.21\right)$.

Pneumothorax: six studies $(7,13,17,19,22,24)$ were included, with 160 and 180 patients in the non-survivor and survivor groups, respectively. The results showed that pneumothorax was a risk factor of mortality from $\mathrm{PcP}$ in non-HIV patients (OR
2.55, 95\% CI 1.13 to $5.77, P=0.02$; Figure $3 B$ ). No significant heterogeneity was found in this analysis $\left(I^{2}=0 \%, P=0.45\right)$.

PcP prophylaxis: seven studies $(6,9,10,12,14,16,19)$ were included, with 214 and 426 patients in the non-survivor and survivor groups, respectively. The results showed that the association between $\mathrm{PcP}$ prophylaxis and mortality was insignificant (OR 1.43, 95\% CI 0.75 to $2.71, P=0.28$; Figure $3 \mathrm{C}$ ). No significant heterogeneity was found in this analysis $\left(I^{2}=0 \%, P=0.67\right)$.

The use of corticosteroids after admission: eight studies ( 7 , $10,14,16,19,21,22,24)$ were included, with 245 and 430 patients in the non-survivor and survivor groups, respectively. The results showed that the use of corticosteroids after admission was not a risk factor of mortality from $\mathrm{PcP}$ in non-HIV patients (OR 1.44, 95\% CI, 0.94 to $2.22 ; P=0.1$; Figure $3 D$ ). No significant heterogeneity was found in this analysis $\left(I^{2}=8 \%, P=0.36\right)$.

Invasive ventilation during hospitalization: twelve studies $(7,8,10,12,14-16,18,19,21,23,24)$ were included, with 278 and 571 patients in the non-survivor and survivor groups, respectively. After the heterogeneity test $\left(I^{2}=54 \%, P=0.01\right)$, the random-effects model was used. The results showed that invasive ventilation during hospitalization was a risk factor of mortality from PcP in non-HIV patients (OR 29.24, 95\% CI 13.09 to 65.33, $P<0.00001$; Figure 3E). 


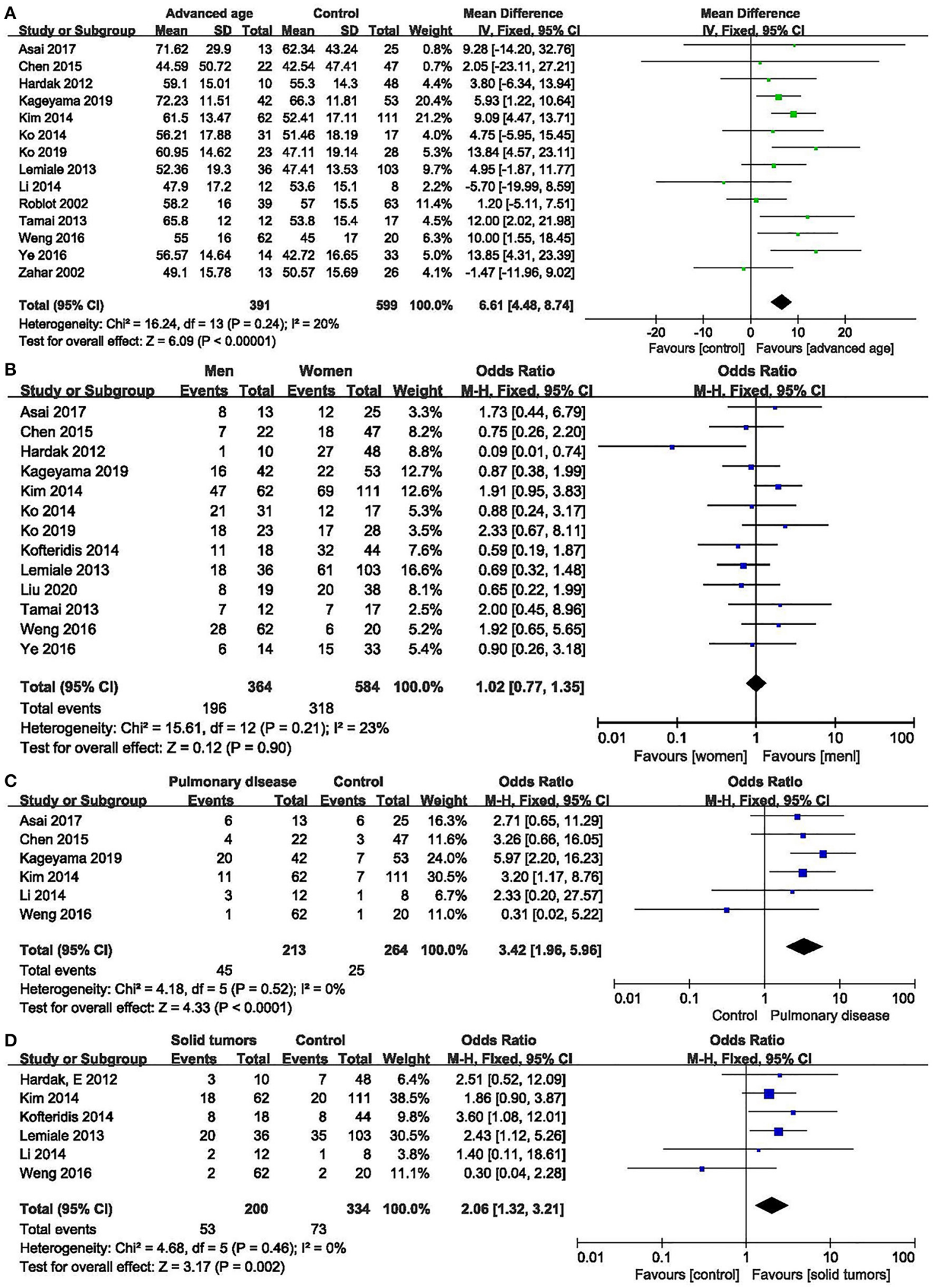

FIGURE 2 | Non-modifiable factors. (A) Forest plots (fixed effects model) of meta-analysis on the association between age and the risk of mortality in non-HIV-related Pneumocystis pneumonia. (B) Forest plots (fixed effects model) of meta-analysis on the association between sex and the risk of mortality in non-HIV-related Pneumocystis pneumonia. (C) Forest plots (fixed effects model) of meta-analysis on the association between pulmonary disease and the risk of mortality in non-HIV-related Pneumocystis pneumonia. (D) Forest plots (fixed effects model) of meta-analysis on the association between solid tumors and the risk of mortality in non-HIV-related Pneumocystis pneumonia. 


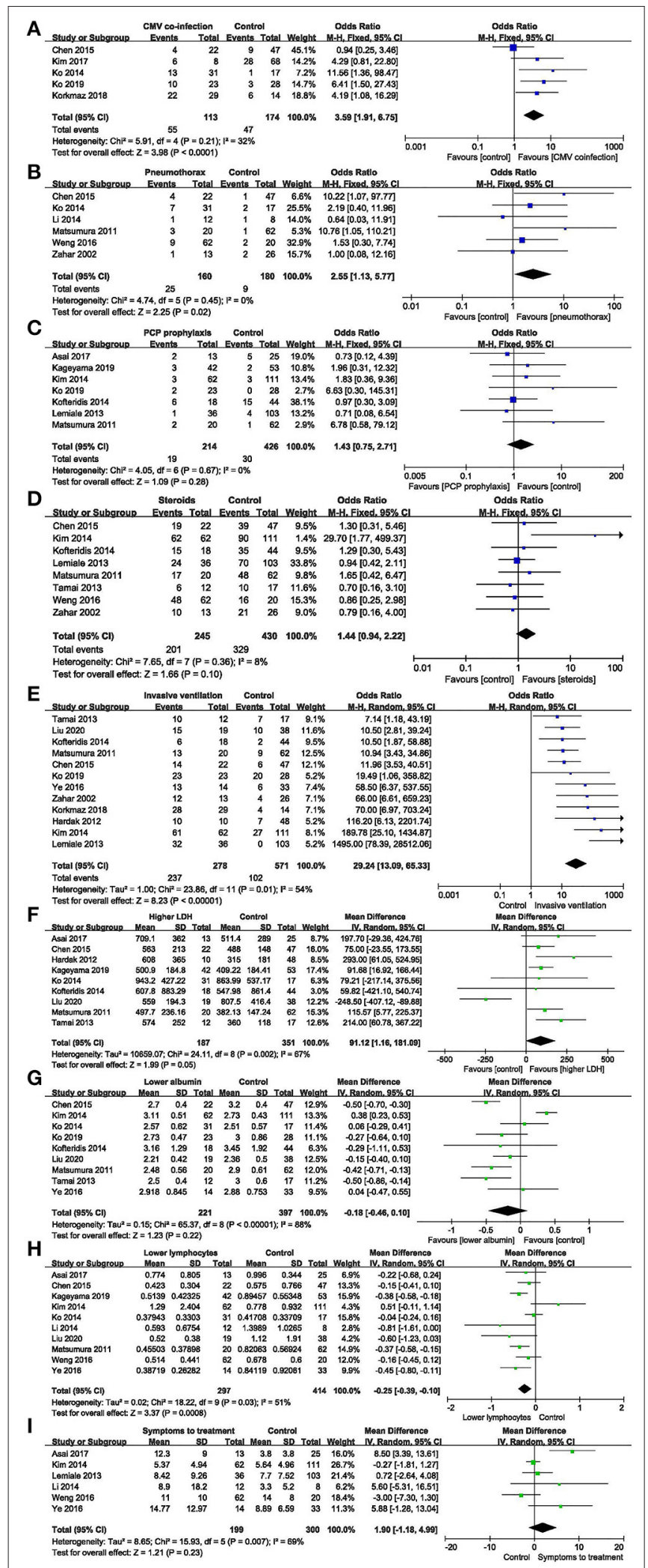

FIGURE 3 | Modifiable factors. (A) Forest plots (fixed effects model) of meta-analysis on the association between cytomegalovirus co-infection and

(Continued)
FIGURE 3 | the risk of mortality in non-HIV-related Pneumocystis pneumonia. (B) Forest plots (fixed effects model) of meta-analysis on the association between pneumothorax and the risk of mortality in non-HIV-related Pneumocystis pneumonia. (C) Forest plots (fixed effects model) of meta-analysis on the association between prophylaxis and the risk of mortality in non-HIV-related Pneumocystis pneumonia. (D) Forest plots (fixed effects model) of meta-analysis on the association between the use of corticosteroids after admission and the risk of mortality in non-HIV-related Pneumocystis pneumonia. (E) Forest plots (random effects model) of meta-analysis on the association between invasive ventilation during hospitalization and the risk of mortality in non-HIV-related Pneumocystis pneumonia. (F) Forest plots (random effects model) of meta-analysis on the association between lactate dehydrogenase and the risk of mortality in non-HIV-related Pneumocystis pneumonia. (G) Forest plots (random effects model) of meta-analysis on the association between albumin and the risk of mortality in non-HIV-related Pneumocystis pneumonia. (H) Forest plots (random effects model) of meta-analysis on the association between lymphocytes and the risk of mortality in non-HIV-related Pneumocystis pneumonia. (I) Forest plots (random effects model) of meta-analysis on the association between time from onset of symptoms to treatment and the risk of mortality in non-HIV-related Pneumocystis pneumonia.

Lactate dehydrogenase (LDH): nine studies (6-9, 13, 14, 18, 19, 21) were included, with 187 and 351 patients in the non-survivor and survivor groups, respectively. After the heterogeneity test $\left(I^{2}=67 \%, P=0.002\right)$, the random effects model was used, and the results showed that $\mathrm{LDH}$ was a risk factor of mortality from $\mathrm{PcP}$ in non-HIV patients (mean difference $=91.12,95 \%$ CI 1.16 to $181.09, P=0.05$; Figure $3 F$ ).

Albumin: nine studies $(7,10,12-14,18,19,21,23)$ were included, with 221 and 397 patients in the non-survivor and survivor groups, respectively. After the heterogeneity test $\left(I^{2}=\right.$ $88 \%, P<0.00001)$, the random effects model was used, and the results showed that albumin was not a risk factor of mortality from $\mathrm{PcP}$ in non-HIV patients (mean difference $=-0.18,95 \%$ $\mathrm{CI}-0.46$ to $0.10, P=0.22$; Figure $3 \mathrm{G})$.

Lymphocyte count: ten studies $(6,7,9,10,13,18,22,23)$ were included, with 297 and 414 patients in the non-survivor and survivor groups, respectively. After the heterogeneity test $\left(I^{2}=51 \%, P=0.03\right)$, the random effects model was used, and the results showed that lymphocyte count was a risk factor of mortality from PcP in non-HIV patients (mean difference = $-0.25,95 \% \mathrm{CI}-0.39$ to $-0.10, P=0.0008$; Figure $3 \mathrm{H}$ ).

Time from onset of symptoms to treatment: six studies (6, $10,16,17,22,23)$ were included, with 199 and 300 patients in the non-survivor and survivor group, respectively. After the heterogeneity test $\left(I^{2}=69 \%, P=0.007\right)$, the random-effects model was used, and the results showed that time from onset of symptoms to treatment was not a risk factor of mortality from $\mathrm{PcP}$ in non-HIV patients (mean difference $=1.90,95 \% \mathrm{CI}-1.18$ to $4.99, P=0.23$; Figure 3 I).

\section{DISCUSSION}

Both non-modifiable and modifiable risk factors can influence the mortality of PcP. Our meta-analysis systematically pooled 19 studies (including 1,310 non-HIV patients with $\mathrm{PcP}$ ), 
which reported the prognostic factors in these patients. In the present study, age, concomitant with other pulmonary diseases at diagnosis of PcP, solid tumors, CMV co-infection, LDH, lymphocyte count, invasive ventilation during hospitalization, and pneumothorax were risk factors of mortality from non-HIVrelated PcP. Some findings in our study were novel and deserve further discussion.

Advanced age is associated with a worse $\mathrm{PcP}$ prognosis in HIV-negative subjects (25-27). This study also found that age is a risk factor for mortality from $\mathrm{PcP}$, which might be related to the progressive decline of somatic function with increasing age.

Our results revealed that in HIV-negative patients, PcP mortality was influenced by underlying pulmonary disease (refers to concomitant with other pulmonary diseases at diagnosis of $\mathrm{PcP}$ ), and an increasing number of reports have described the pulmonary colonization of $\mathrm{PcP}$ in immunosuppressive patients with underlying pulmonary diseases $(28,29)$. A previous report indicated that up to $33.8 \%$ of patients with interstitial lung diseases are colonized with pneumocystis (30), which may contribute to the severity of the disease. Moreover, Enomoto et al. (31) conducted the first study focusing on HIV-negative PcP patients with underlying pulmonary diseases and found that all the five HIV-negative PcP patients with no underlying pulmonary disease survived, whereas nine of the $12 \mathrm{HIV}$-negative PcP patients with underlying pulmonary disease died. The current literature has not identified the mechanism by which pulmonary disease affects the prognosis of PcP. We assume that chronic pulmonary disease might lead to the destruction of the lung structure, making pneumocystis in the lungs more likely to progress, thereby increasing mortality.

The pooled results of this meta-analysis demonstrate that solid tumors are one of the comorbidities associated with an increased mortality rate in non-HIV PcP patients, which might be related to the immunosuppressive state, making it easier for pathogens to spread. New treatment of solid tumors, including more intensive chemotherapy, increases the survival rate of patients with malignancies. However, such advanced states increase the risk of treatment-related life-threatening complications, which leads to increased mortality $(32,33)$.

Our analysis of five articles found that CMV co-infection increased mortality in non-HIV PcP patients, although there was no significant difference in mortality among HIV patients with PcP based on their CMV infection status (34-37). In contrast to the above results, some previous researchers found that pulmonary CMV co-infection does not increase the risk of death $(11,38)$. Korkmaz et al. (15) found that the development of acute respiratory distress syndrome (ARDS) and the requirement for mechanical ventilation are more common in the CMV coinfection group, requiring a longer duration of stay in the intensive care unit (ICU), while CMV co-infection was not an independent risk factor in multivariate analysis for mortality. In kidney transplant recipients with PcP, mortality became doubled in the PcP combined with CMV group than that in the PcP only group, but the difference was not statistically significant (39). These differences in results might on account of the heterogeneity of HIV-negative patients in different studies, including different underlying diseases. Furthermore, the differences in the copy number of CMV between studies, reflecting whether CMV is active or pathogenic, might also relate to the heterogeneity of these results [higher CMV DNA load in the bronchoalveolar lavage fluid was positively associated with increased mortality (38)]. Therefore, further large-scale prospective studies are needed to determine whether CMV infection in non-HIV PcP patients affects the prognosis.

As expected, high serum LDH levels are a risk factor affecting the prognosis of PcP. LDH is considered as a predictive parameter of disease severity as well as a marker for assessing the condition of patients during treatment. It has also been found that higher $\mathrm{LDH}$ levels at PcP diagnosis is a risk factor for death (40). The serum $\mathrm{LDH}$ in $\mathrm{PcP}$ patients, which is released from the cells after the cytoplasmic membrane is damaged, might increase after the lung injury caused by the pathogen.

The combined analysis of 10 studies in the present study showed that a low lymphocyte count was associated with death. Most of the patients in our study were immunosuppressed, and lymphocyte count may be a helpful marker to determine the risk of PcP in immunosuppressed patients without HIV (40). Meanwhile, when infected with PcP in non-HIV patients, the lymphocyte count can also be used to predict mortality.

Based on our findings, invasive ventilation during hospitalization was associated with increased mortality. This finding is consistent with a previous study (41). Invasive ventilation often indicates a state of severe hypoxemia, and multiple organs are also likely to be in a state of failure or ARDS. Therefore, it is expected that the mortality rate will increase significantly, and this may be explained by ventilator-associated pneumonia. To correct hypoxia, the set ventilator parameters are generally high (26). This often leads to ventilator-associated lung injuries. Additional studies are required to identify approaches to improving the protective lung ventilation strategies for this population. Barotrauma, including pneumothorax, pneumomediastinum and pneumohypoderma, caused by invasive ventilation, can also explain the extremely poor prognosis (42). Pneumothorax is currently an unsolved problem in PcP. The development of pneumothorax is independently associated with increased mortality in $\mathrm{PcP}$ patients without $\mathrm{HIV}$ infection (43).

Hypoalbuminemia is reported as an independent risk factor of mortality in a study performed on HIV patients with $\mathrm{PcP}$ infection (44), and it has also been reported as an independent risk factor for non-HIV $(45,46)$. Albumin has antioxidant activity and can protect the cells from oxidative stress in sepsis. It is also an indicator of inflammation, suggesting the severity of the disease. Albumin levels decrease during acute and chronic inflammation since the cytokines inhibit its synthesis in the liver (47). However, our analysis showed no association between low serum albumin levels and mortality. That the results were statistically significant may be related to the relatively small sample size.

It is worrying that $\mathrm{PcP}$ prophylaxis was not generally administered in immunocompromised non-HIV patients. Our analysis showed that only $7.66 \%(49 / 640)$ of HIV-negative patients with $\mathrm{PcP}$ received appropriate prophylaxis before the onset of disease. No significant differences were observed in 
mortality between patients with or without prophylaxis in the current meta-analysis. This result might be affected by the degree of illness in different populations reported in different studies and the limited sample sizes, and therefore cannot be extrapolated. Prophylaxis is effective in susceptible individuals and is administered in most transplant centers. The American Society of Transplantation recommends general prophylaxis for 6-12 months after solid organ transplantation. If there is anti-rejection therapy, long-term neutropenia, or corticosteroid therapy with a dose of $>20 \mathrm{mg}$ prednisolone equivalent for more than 4 weeks, preventive measures should be extended. Lifelong prophylaxis is recommended for patients with chronic CMV infection, a history of PcP infection, or after the lung or small-bowel transplantation (48). The Kidney Disease Improving Global Outcomes (KDIGO) guidelines recommend prophylaxis with trimethoprim/sulfamethoxazole daily for 3-6 months, and for 6 weeks after anti-rejection therapy in kidney transplant patients (49). In summary, PcP prevention is necessary.

The use of adjunctive steroids during hospitalization may not improve $\mathrm{PcP}$ outcomes in non-HIV patients. For HIVnegative patients with $\mathrm{PcP}$, there is no strong evidence that these patients may benefit from adjunctive steroids (50). Two previous studies $(51,52)$ analyzed the effects of steroids on non-HIV patients with severe $\mathrm{PcP}(\mathrm{PaO} 2<70 \mathrm{mmHg})$ and reported that adjunctive steroids failed to reduce hospital mortality. Another study found that high-dose steroid treatment $(\geq 1 \mathrm{mg} / \mathrm{kg} /$ day prednisone equivalent) was an independent predictor of ICU mortality (51). However, some factors may have an impact on the role of adjunctive steroids in mortality, such as the dose of adjunctive steroids, severity of the disease, whether adjunctive steroids are added for the treatment of PcP, and whether the patient has used adjunctive steroids to treat the primary disease before the PcP. These factors were mixed in the included studies, and this question needs to be answered by a well-designed large randomized clinical trial. Therefore, the decision to add steroids as an adjunctive treatment should be individualized.

Early diagnosis and empirical treatment initiation could improve mortality in non-HIV-PcP patients $(16,53,54)$. Treatment delay has previously been considered as a factor associated with poor prognosis in patients with PcP (55). However, this meta-analysis did not find time from symptom onset to treatment was an independent poor prognostic factor for non-HIV PcP. There are many confounding factors, including the large top tertiary hospitals we had included. Many of the patients admitted to these tertiary hospitals were referral patients who were financially capable or in critical condition, probably resulting in the mixed conclusions. We believe that more patients with the same basic characteristics are required to further explore this finding.

\section{LIMITATION}

There are some limitations to the present meta-analysis. Firstly, our meta-analysis is based on observational data, and therefore, the results are not as robust as those of randomized controlled trials. Secondly, the characteristics of the included patients in different studies differed, including the methods of diagnosis of PcP, sample selection, and follow-up, which might contribute to the statistical and clinical heterogeneity. Moreover, the limited sample size may also influence the application of the results. Thirdly, only English language studies were included, and this review did not include unpublished researches or those published in the "gray literature." Thus, differences about region, race and other influencing factors may not been fully reflected.

\section{CONCLUSION}

The mortality rate of non-HIV-infected patients with PcP was still high. Although high-level evidence is lacking, this study demonstrates that age, concomitant with other pulmonary diseases at diagnosis of $\mathrm{PcP}$, solid tumors, $\mathrm{CMV}$ co-infection, LDH, lymphocyte count, invasive ventilation during hospitalization, and pneumothorax are risk factors of mortality from non-HIV-related Pneumocystis pneumonia. However, data supporting several other indices are insufficient. Hence, further large-scale studies are required to verify these findings. Improved knowledge of prognostic factors is crucial to guide early treatment.

\section{DATA AVAILABILITY STATEMENT}

The original contributions presented in the study are included in the article/supplementary materials. Further inquiries can be directed to the corresponding author.

\section{AUTHOR CONTRIBUTIONS}

QZ was involved in the administrative support, conception and design of the manuscript, data interpretation, reviewed, and revised the manuscript. YW was involved in the conception and design of the manuscript, collection and assembly of the data, data analysis, and drafted the initial manuscript. XZ and MS was involved in the collection and assembly of data and drafted the initial manuscript. XH was involved in the conception and design of the manuscript, reviewed, and revised the manuscript. TS was involved in the conception, design of the manuscript, and data interpretation. GF was involved in the critically reviewed the manuscript for important intellectual content. All authors contributed to the article and approved the submitted version.

\section{FUNDING}

This work was supported by the Zhejiang University special scientific research fund for COVID-19 prevention and control (grant number 2020XGZX008).

\section{ACKNOWLEDGMENTS}

The authors would like to acknowledge colleagues for helpful comments. 


\section{REFERENCES}

1. Reid AB, Chen SC, Worth LJ. Pneumocystis jirovecii pneumonia in non-HIVinfected patients: new risks and diagnostic tools. Curr Opin Infect Dis. (2011) 24:534-44. doi: 10.1097/QCO.0b013e32834cac17

2. Wickramasekaran RN, Jewell MP, Sorvillo F, Kuo T. The changing trends and profile of pneumocystosis mortality in the United States, 1999-2014. Mycoses. (2017) 60:607-15. doi: 10.1111/myc.12636

3. Maini R, Henderson KL, Sheridan EA, Lamagni T, Nichols G, Delpech V, et al. Increasing pneumocystis pneumonia, England, UK, 2000-2010. Emerg Infect Dis. (2013) 19:386-92. doi: 10.3201/eid1903.121151

4. Bollee G, Sarfati C, Thiery G, Bergeron A, de Miranda S, Menotti J, et al. Clinical picture of Pneumocystis jiroveci pneumonia in cancer patients. Chest. (2007) 132:1305-10. doi: 10.1378/chest.07-0223

5. Wells G, Shea B, O'Connell D. The Newcastle-Ottawa Scale (NOS) for Assessingthe Quality of Nonrandomised Studies in Meta-Analyses. Available online at: http://www.ohri.ca/programs/clinical_epidemiology/oxford.asp (accessed May 20, 2021).

6. Asai N, Motojima S, Ohkuni $\mathrm{Y}$, Matsunuma R, Iwasaki $\mathrm{T}$, Nakashima K, et al. Clinical manifestations and prognostic factors of Pneumocystis jirovecii pneumonia without HIV. Chemotherapy. (2017) 62:343-9. doi: 10.1159/000477332

7. Chen M, Tian X, Qin F, Zhou J, Liu J, Wang M, et al. Pneumocystis pneumonia in patients with autoimmune diseases: a Retrospective study focused on clinical characteristics and prognostic factors related to death. PLoS ONE. (2015) 10:e0139144. doi: 10.1371/journal.pone.0139144

8. Hardak E, Neuberger A, Yigla M, Berger G, Finkelstein R, Sprecher H, et al. Outcome of Pneumocystis jirovecii pneumonia diagnosed by polymerase chain reaction in patients without human immunodeficiency virus infection. Respirology. (2012) 17:681-6. doi: 10.1111/j.1440-1843.2012.02158.x

9. Kageyama T, Furuta S, Ikeda K, Kagami SI, Kashiwakuma D, Sugiyama $\mathrm{T}$, et al. Prognostic factors of pneumocystis pneumonia in patients with systemic autoimmune diseases. PLoS One. (2019) 14:e0214324. doi: 10.1371/journal.pone.0214324

10. Kim SJ, Lee J, Cho YJ, Park YS, Lee CH, Yoon HI, et al. Prognostic factors of Pneumocystis jirovecii pneumonia in patients without HIV infection. J Infect. (2014) 69:88-95. doi: 10.1016/j.jinf.2014.02.015

11. Kim T, Park SY, Lee HJ, Kim SM, Sung H, Chong YP, et al. Assessment of cytomegalovirus and cell-mediated immunity for predicting outcomes in non-HIV-infected patients with Pneumocystis jirovecii pneumonia. Medicine. (2017) 96:e7243. doi: 10.1097/MD.0000000000007243

12. Ko RE, Na SJ, Huh K, Suh GY, Jeon K. Association of time-to-treatment with outcomes of pneumocystis pneumonia with respiratory failure in HIV-negative patients. Respir Res. (2019) 20:213. doi: 10.1186/s12931-0191188-6

13. Ko Y, Jeong BH, Park HY, Koh WJ, Suh GY, Chung MP, et al. Outcomes of pneumocystis pneumonia with respiratory failure in HIV-negative patients. $J$ Crit Care. (2014) 29:356-61. doi: 10.1016/j.jcrc.2013.12.005

14. Kofteridis DP, Valachis A, Velegraki M, Antoniou M, Samonis G. Predisposing factors, clinical characteristics and outcome of Pneumonocystis jirovecii pneumonia in HIV-negative patients. J Infect Chemother. (2014) 20:4126. doi: 10.1016/j.jiac.2014.03.003

15. Korkmaz EP, Toreyin ZN, Nahid P, Doskaya M, Caner A, Turgay $\mathrm{N}$, et al. The association between cytomegalovirus co-infection with pneumocystis pneumonia and mortality in immunocompromised non-HIV patients. Clin Respir J. (2018) 12:2590-7. doi: 10.1111/crj. 12961

16. Lemiale V, Debrumetz A, Delannoy A, Alberti C, Azoulay E. Adjunctive steroid in hIV-negative patients with severe pneumocystis pneumonia. Respir Res. (2013) 14:87-7. doi: 10.1186/1465-9921-14-87

17. Li MC, Lee NY, Lee CC, Lee HC, Chang CM, Ko WC. Pneumocystis jiroveci pneumonia in immunocompromised patients: delayed diagnosis and poor outcomes in non-HIV-infected individuals. J Microbiol Immunol Infect. (2014) 47:42-7. doi: 10.1016/j.jmii.2012.08.024

18. Liu Y, Zheng K, Liu Y, Zhu H. Pneumocystis jirovecii pneumonia in patients with nephrotic syndrome: application of lymphocyte subset analysis in predicting clinical outcomes. Can J Infect Dis Med Microbiol. (2020) 93:18. doi: $10.1155 / 2020 / 4631297$
19. Matsumura Y, Shindo Y, Iinuma Y, Yamamoto M, Shirano M, Matsushima A, et al. Clinical characteristics of pneumocystis pneumonia in non-HIV patients and prognostic factors including microbiological genotypes. BMC Infect Dis. (2011) 11:76. doi: 10.1186/1471-2334-11-76

20. Roblot F, Godet C, Le Moal G, Garo B, Faouzi SM, Dary M, et al. Analysis of underlying diseases and prognosis factors associated with Pneumocystis carinii pneumonia in immunocompromised HIV-negative patients. Eur J Clin Microbiol Infect Dis. (2002) 21:523-31. doi: 10.1007/s10096-002-0758-5

21. Tamai K, Tachikawa R, Tomii K, Nagata K, Otsuka K, Nakagawa $\mathrm{A}$, et al. Prognostic value of bronchoalveolar lavage in patients with non-HIV pneumocystis pneumonia. Jpn J Med. (2014) 53:1113-7. doi: 10.2169/internalmedicine.53.0520

22. Weng L, Huang X, Chen L, Feng LQ, Jiang W, Hu XY, et al. Prognostic factors for severe Pneumocystis jiroveci pneumonia of non-HIV patients in intensive care unit: a bicentric retrospective study. BMC Infect Dis. (2016) 16:528-8. doi: 10.1186/s12879-016-1855-x

23. Ye WL, Tang N, Wen YB, Li H, Li MX, Du B, et al. Underlying renal insufficiency: the pivotal risk factor for Pneumocystis jirovecii pneumonia in immunosuppressed patients with non-transplant glomerular disease. Int Urol Nephrol. (2016) 48:1863-71. doi: 10.1007/s11255-016-1324-x

24. Zahar JR, Robin M, Azoulay E, Fieux F, Nitenberg G, Schlemmer B. Pneumocystis carinii pneumonia in critically ill patients with malignancy: a Descriptive study. Clin Infect Dis. (2002) 35:929-34. doi: 10.1086/342338

25. Ricciardi A, Gentilotti E, Coppola L, Maffongelli G, Cerva C, Malagnino $\mathrm{V}$, et al. Infectious disease ward admission positively influences $P$. jiroveci pneumonia $(\mathrm{PjP})$ outcome: a retrospective analysis of $116 \mathrm{HIV}$ positive and HIV-negative immunocompromised patients. PLoS ONE. (2017) 12:e0176881. doi: 10.1371/journal.pone.0176881

26. Roux A, Canet E, Valade S, Gangneux-Robert F, Hamane S, Lafabrie A, et al. Pneumocystis jirovecii pneumonia in patients with or without AIDS, France. Emerg Infect Dis. (2014) 20:1490-7. doi: 10.3201/eid2009.131668

27. Maertens J, Cesaro S, Maschmeyer G, Einsele H, Donnelly JP, Alanio A, et al. ECIL guidelines for preventing Pneumocystis jirovecii pneumonia in patients with haematological malignancies and stem cell transplant recipients. J Antimicrob Chemother. (2016) 71:2397-404. doi: 10.1093/jac/dkw157

28. Probst M, Ries H, Schmidt-Wieland T, Serr A. Detection of pneumocystis carinii DNA in patients with chronic lung diseases. Eur J Clin Microbiol Infect Dis. (2000) 19:644-5. doi: 10.1007/s100960000329

29. Sing A, Geiger AM, Hogardt M, Heesemann J. Pneumocystis carinii carriage among cystic fibrosis patients, as detected by nested PCR. J Clin Microbiol. (2001) 39:2717-8. doi: 10.1128/JCM.39.7.2717-2718.2001

30. Vidal S, Horra CDL, Martín J, Montes-Cano MA, Calderón EJ. Pneumocystis jirovecii colonisation in patients with interstitial lung disease. Clin Microb Infect. (2010) 12:231-5. doi: 10.1111/j.1469-0691.2005.01337.x

31. Enomoto T, Azuma A, Kohno A, Kaneko K, Saito H, Kametaka M, et al. Differences in the clinical characteristics of Pneumocystis jirovecii pneumonia in immunocompromized patients with and without HIV infection. Respirology. (2010) 15:126-31. doi: 10.1111/j.1440-1843.2009.01660.x

32. Sepkowitz KA. Pneumocystis carinii pneumonia in patients without AIDS. Clin Infect Dis. (1993) 17(Suppl. 2):S41622. doi: 10.1093/clinids/17.Supplement_2.S416

33. Sepkowitz KA, Brown AE, Telzak EE, Gottlieb S, Armstrong D. Pneumocystis carinii pneumonia among patients without AIDS at a cancer hospital. JAMA. (1992) 267:832-7. doi: 10.1001/jama.267.6.832

34. Bozzette SA, Arcia J, Bartok AE, McGlynn LM, McCutchan JA, Richman DD, et al. Impact of Pneumocystis carinii and cytomegalovirus on the course and outcome of atypical pneumonia in advanced human immunodeficiency virus disease. J Infect Dis. (1992) 165:93-8. doi: 10.1093/infdis/165.1.93

35. Jacobson MA, Mills J, Rush J, Peiperl L, Seru V, Mohanty PK, et al. Morbidity and mortality of patients with AIDS and first-episode Pneumocystis carinii pneumonia unaffected by concomitant pulmonary cytomegalovirus infection. Am Rev Respir Dis. (1991) 144:6-9. doi: 10.1164/ajrccm/144.1.6

36. Kim T, Moon SM, Sung H, Kim MN, Kim SH, Choi SH, et al. Outcomes of non-HIV-infected patients with pneumocystis pneumonia and concomitant pulmonary cytomegalovirus infection. Scand J Infect Dis. (2012) 44:6707. doi: 10.3109/00365548.2011.652665

37. Millar AB, Patou G, Miller RF, Grundy JE, Katz DR, Weller IV, et al. Cytomegalovirus in the lungs of patients with aIDS. 
Respiratory pathogen or passenger. Am Rev Respir Dis. (1990) 141:1474-7. doi: 10.1164/ajrccm/141.6.1474

38. Yu Q, Jia P, Su L, Zhao H, Que C. Outcomes and prognostic factors of non-HIV patients with Pneumocystis jirovecii pneumonia and pulmonary CMV co-infection: a Retrospective cohort study. BMC Infect Dis. (2017) 17:392. doi: 10.1186/s12879-017-2492-8

39. Lee S, Park Y, Kim SG, Ko EJ, Chung BH, Yang CW. The impact of cytomegalovirus infection on clinical severity and outcomes in kidney transplant recipients with Pneumocystis jirovecii pneumonia. Microbiol Immunol. (2020) 64:356-65. doi: 10.1111/1348-0421.12778

40. Jin F, Liu XH, Chen WC, Fan ZL, Wang HL. High initial $(1,3)$ betad-Glucan concentration may be a predictor of satisfactory response of $\mathrm{C}$ aspofungin combined with TMP/SMZ for HIV-negative patients with moderate to severe Pneumocystis jirovecii pneumonia. Int J Infect Dis. (2019) 88:141-8. doi: 10.1016/j.ijid.2019.08.015

41. Glück T, Geerdes-Fenge HF, Straub RH, Raffenberg M, Lang B, Lode H, et al. Pneumocystis carinii pneumonia as a complication of immunosuppressive therapy. Infection. (2000) 28:227-30. doi: 10.1007/s150100070041

42. Kollef $\mathrm{MH}$. Ventilator-associated pneumonia: the role of emerging therapies and diagnostics. Chest. (2015) 147:1448-50. doi: 10.1378/chest. 14-2745

43. Safe IP, Oliveira VC, Marinho PM, Lacerda MV, Damian MM. Spontaneous pneumothorax: a fatal complication in hIV-infected patients. Braz J Infect Dis. (2014) 18:466-6. doi: 10.1016/j.bjid.2014.04.004

44. Festic E, Gajic O, Limper AH, Aksamit TR. Acute respiratory failure due to pneumocystis pneumonia in patients without human immunodeficiency virus infection: outcome and associated features. Chest. (2005) 128:5739. doi: $10.1378 /$ chest.128.2.573

45. Wang M, Dai X, Huang Y, Sun J, Dong X, Guo Y, et al. The presence of Pneumocystis jirovecii DNA in plasma is associated with a higher mortality rate in patients with AIDS-associated pneumocystis pneumonia. Med Mycol. (2018) 5:582-7. doi: 10.1093/mmy/myy110

46. Yoshida A, Kamata N, Yamada A, Yokoyama Y, Omori T, Fujii T, et al. Risk factors for mortality in Pneumocystis jirovecii pneumonia in patients with inflammatory bowel disease. Inflamm Intest Dis. (2019) 3:16772. doi: 10.1159/000495035

47. Kumagai S, Arita M, Koyama T, Kumazawa T, Inoue D, Nakagawa A, et al. Prognostic significance of crazy paving ground grass opacities in non-HIV Pneumocystis jirovecii pneumonia: an observational cohort study. BMC Pulm Med. (2019) 19:47. doi: 10.1186/s12890-019-0813-y

48. Di Napoli M, Behrouz R, Topel CH, Misra V, Pomero F, Giraudo A, et al. Hypoalbuminemia, systemic inflammatory response syndrome, and functional outcome in intracerebral hemorrhage. J Crit Care. (2017) 41:24753. doi: 10.1016/j.jcrc.2017.06.002

49. Martin SI, Fishman JA. Pneumocystis pneumonia in solid organ transplantation. Am J Transplant. (2013) 13(Suppl. 4):2729. doi: 10.1111/ajt.12119

50. Kasiske BL, Zeier MG, Chapman JR, Craig JC, Ekberg H, Garvey CA, et al. KDIGO clinical practice guideline for the care of kidney transplant recipients: a summary. Kidney Int. (2010) 77:299-311. doi: 10.1038/ki.2009.377

51. Delclaux C, Zahar JR, Amraoui G, Leleu G, Lebargy F, Brochard L, et al. Corticosteroids as adjunctive therapy for severe pneumocystis carinii pneumonia in non-human immunodeficiency virus-infected patients: retrospective study of 31 patients. Clin Infect Dis. (1999) 29:67072. doi: 10.1086/598651

52. Moon SM, Kim T, Sung H, Kim MN, Kim SH, Choi SH, et al. Outcomes of moderate-to-severe pneumocystis pneumonia treated with adjunctive steroid in non-HIV-infected patients. Antimicrob Agents Chemother. (2011) 55:46138. doi: 10.1128/AAC.00669-11

53. Asai N, Motojima S, Ohkuni Y, Matsunuma R, Nakashima K, Iwasaki T, et al. Early diagnosis and treatment are crucial for the survival of pneumocystis pneumonia patients without human immunodeficiency virus infection. $J$ Infect Chemother. (2012) 18:898-905. doi: 10.1007/s10156-012-0441-4

54. Asai N, Katsuda E, Hamanaka R, Kosaka K, Matsubara A, Nishimura M, et al. The ATS/ERS/JRS/ALAT statement "IPF by HRCT" could predict acute exacerbation of interstitial lung disease in non-small cell lung cancer. Tumori. (2017) 103:60-5. doi: 10.5301/tj.5000574

55. Kameda H, Tokuda H, Sakai F, Johkoh T, Mori S, Yoshida Y, et al. Clinical and radiological features of acute-onset diffuse interstitial lung diseases in patients with rheumatoid arthritis receiving treatment with biological agents: importance of pneumocystis pneumonia in japan revealed by a multicenter study. Intern Med. (2011) 50:305-13. doi: 10.2169/internalmedicine.50.4508

Conflict of Interest: The authors declare that the research was conducted in the absence of any commercial or financial relationships that could be construed as a potential conflict of interest.

Copyright (C) 2021 Wang, Zhou, Saimi, Huang, Sun, Fan and Zhan. This is an open-access article distributed under the terms of the Creative Commons Attribution License (CC BY). The use, distribution or reproduction in other forums is permitted, provided the original author(s) and the copyright owner(s) are credited and that the original publication in this journal is cited, in accordance with accepted academic practice. No use, distribution or reproduction is permitted which does not comply with these terms. 